\title{
Aberrant CD3 Expression in a Relapsed Plasma Cell Neoplasm
}

\author{
Jai-Hyang Go \\ Department of Pathology, Dankook University College of Medicine, Cheonan, Korea
}

\begin{abstract}
Aberrant expression of $\mathrm{CD} 3$ is extremely rare in plasma cell neoplasm (PCN), and only a few cases have been reported. ${ }^{1-6}$ Moreover, no studies have compared the expression pattern of $\mathrm{CD} 3$ between initial tumor and recurrent tumor in PCN. Herein, we describe an unusual case of $\mathrm{PCN}$, which initially presented as CD3-negative plasmacytoma but exhibited aberrant CD3 expression at relapse. The tumor cells in both the initial tumor and relapsed tumor were positive for Epstein-Barr virus (EBV)-encoded RNA (EBER) in situ hybridization (ISH).
\end{abstract}

\section{CASE REPORT}

A 64-year-old man was admitted due to back pain of 2 months. Magnetic resonance imaging (MRI) showed pathologic fracture of the 12th thoracic vertebral body with anterior epidural and both paravertebral extensions (Fig. 1A). Histologic findings of bone biopsy showed differentiated PCN (Fig. 2A), which was positive for $\mathrm{CD} 138$ (Fig. 2B), MUM-1, and CD56 and weakly positive for $\mathrm{CD} 10$, but negative for $\mathrm{CD} 20$ or $\mathrm{CD} 3$ (Fig. 2C) and cyclin D1. The tumor cells were also positive for EBER ISH (Fig. 2D). The proliferation index (Ki-67) was approximately $50 \%$. Bone marrow biopsy was negative. The patient was mildly anemic, and serum creatinine, blood urea nitrogen, and calcium levels were within the normal range. Serum immunoglobulin electrophoresis (EP) revealed a suspicious $\operatorname{IgA} / \lambda$ monoclonal band. No M-proteins were detected in serum or urine protein EP. Serum levels of kappa $(\kappa)$ and lambda $(\lambda)$ free light chains (FLCs) were normal, and serum level of $\operatorname{IgA}$

\section{Corresponding Author}

Jai-Hyang Go

Department of Pathology, Dankook University College of Medicine, 119 Dandae-ro, Dongnam-gu, Cheonan 31116, Korea

Tel: +82-41-550-6972, Fax: +82-41-561-9127, E-mail: cyjy555@hanmail.net

Received: July 21, 2017 Revised: August 22, 2017

Accepted: September 5, 2017 was mildly elevated to $473.0 \mathrm{mg} / \mathrm{dL}$ (normal range, 70 to 400 ). The patient was diagnosed with solitary plasmacytoma and received radiotherapy. Follow-up MRI at 4 months after initial diagnosis revealed multiple bone, muscle, and lymph node involvements (Fig. 1B). Physical examination revealed soft tissue masses in the right forearm, both thighs, and lower left abdomen. Histologically, tumors from the right forearm and lower left abdomen were composed of medium-sized and mononuclear blastic cells admixed with smaller cells showing plasmacytic differentiation, which was consistent with plasmablastic myeloma (PM) (Fig. 2E). The tumor cells were positive for CD138 (Fig. 2F), MUM-1, and CD56 and strongly positive for CD10 and CD3 (Fig. 2G), but negative for CD20 and cyclin D1. The proliferation index (Ki-67) was approximately $80 \%$. The tumor cells were also positive for EBER ISH (Fig. 2H). At the time, the $\mathrm{M}$-band was not yet detected in serum or urine protein $\mathrm{EP}$, but the serum level of $\lambda$ FLC was elevated to $117.2 \mathrm{mg} / \mathrm{L}$ (normal range, 5.71 to 26.3), and $\kappa \mathrm{FLC}$ was $13.8 \mathrm{mg} / \mathrm{L}$ (normal range, 3.3 to 19.4 ). Serum level of $\operatorname{Ig} A$ was much more elevated at $1,230 \mathrm{mg} / \mathrm{dL}$.

This study was approved by the Institutional Review Board of Dankook University Hospital, with informed consent waived (IRB No. 2017-09011).

\section{DISCUSSION}

We describe the first reported case of PCN in which aberrant $\mathrm{CD} 3$ expression is present only in the relapsed tumor, but not in the initial tumor, suggesting that $\mathrm{CD} 3$ expression is associated with disease progression and poor prognosis of $\mathrm{PCN}$.

In the relapsed tumor in this case, plasmablastic lymphoma (PBL) should have been included in the differential diagnosis. A common histogenesis of PBL and PM is suggested with evidence linking these 2 tumors with morphological and immunophe- 

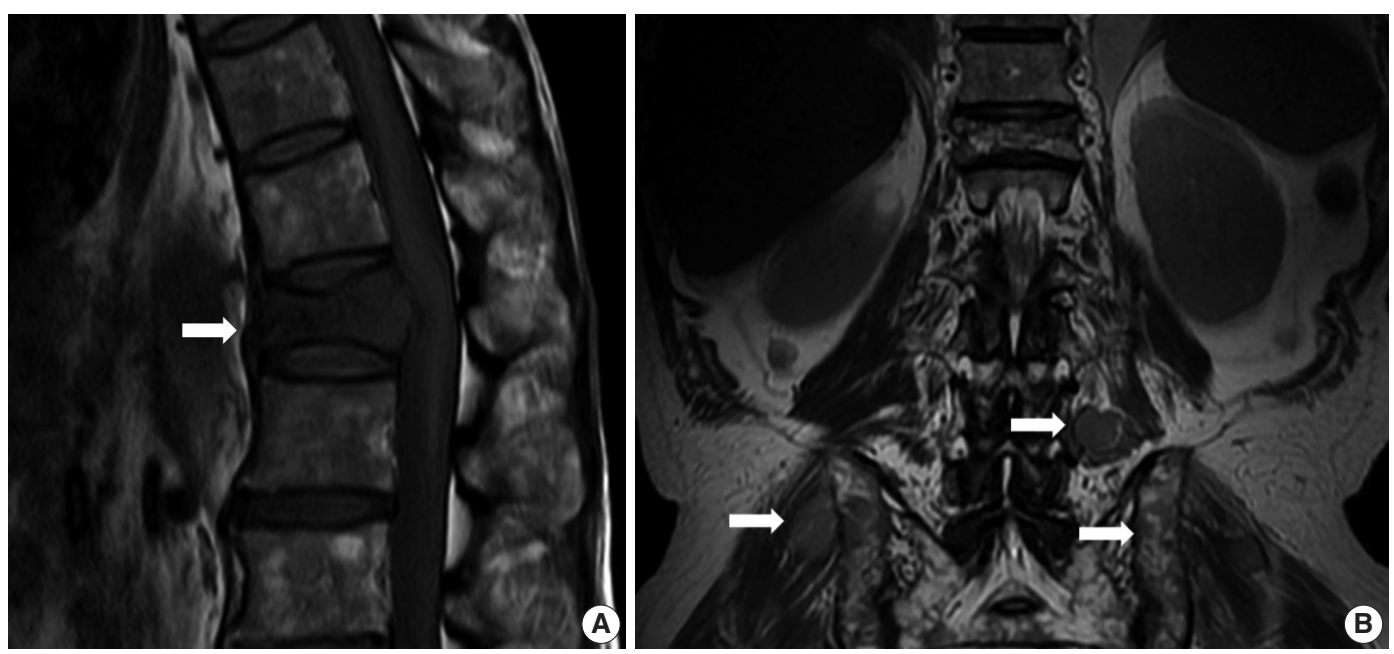

Fig. 1. Magnetic resonance imaging (MRI) showed pathologic fracture of 12th thoracic vertebral body with anterior epidural and both paravertebral extensions at initial presentation (A, arrow). Follow-up MRI at 4 months after initial diagnosis revealed multiple nodular masses in posterior paravertebral muscle, both gluteal muscles, and both iliac bones (B, arrows).

notypic similarities, ${ }^{7}$ including a high proliferation rate and expression of CD56 and CD10. These 2 markers are more often associated with PCN, but are positive in more than half of the cases of $\mathrm{PBL} ;{ }^{8}$ therefore, they cannot be used as definite criteria. Cyclin $\mathrm{D} 1$ is negative in PBL but positive in a subgroup of $\mathrm{PCN} .{ }^{8}$ The distinction between PBL and PM is based largely on clinical presentation and the presence of EBV. PBL has a high association with EBV and is thought to lack the clinicopathological characteristics of PCN, which are monoclonal paraproteinemia, lytic bone lesions, and proliferation of plasma cells in the bone marrow, peripheral blood, or extramedullary sites. ${ }^{7}$ Therefore, high-grade lymphomas with plasmablastic morphology, occurring in an immunocompromised patient, localized primarily in extramedullary sites that are positive for EBV would be designated as PBL. In contrast, PM occurs in patients with preexisting or concurrent clinical evidence of PCN. ${ }^{7}$

Aberrant CD3 expression in B-cell neoplasm is relatively rare. Most cases have been EBV-associated malignancies including pyothorax- or immunodeficiency-associated lymphomas ${ }^{1}$ and PBL. ${ }^{3,9}$ However, a recent study has revealed that EBV-negative tumors with plasmacytic differentiation including plasma cell myeloma and plasmacytoma were the main subset of $\mathrm{CD} 3$-positive B-cell tumors. ${ }^{1}$ However, CD3 expression is still considered to be rare in PCN. Only 9 cases of PCN with aberrant CD3 expression have been reported in the literature (Table 1). ${ }^{1-6}$

Lineage infidelity is uncommon in terminally differentiated B-cell lymphomas, ${ }^{9}$ and neoplastic plasma cells infrequently have aberrant phenotypic characteristics. ${ }^{2}$ Myeloma cells have been found to express a wide array of early and late differentiation markers pertaining to myeloid, monocytic, erythroid, megakaryocytic, and B-cell and T-cell lineages. ${ }^{5}$ However, these aberrant phenotypes have largely been limited to B-cell antigen expression including CD10 and $\mathrm{TdT}{ }^{2}$ and neoplastic plasma cells very rarely express T-cell antigen. ${ }^{2,10}$ An aberrant phenotype is seen mostly in poorly differentiated or anaplastic myelomas associated with poor prognosis. ${ }^{10}$ Therefore, coexpression of nonlineage-restricted markers CD10, CD13, and CD33 on myeloma cells has been associated with poor prognosis. ${ }^{5}$

One study has reported that $\mathrm{T}$ antigen expression was present in 6 patients with multiple myelomas. ${ }^{2}$ Among them, 5 cases were relapsed tumors, and the survival from demonstration of $\mathrm{T}$ antigen expression was very short in these cases, ${ }^{2}$ suggesting that aberrant $\mathrm{T}$ antigen expression can be related to poor prognosis. Two additional relapsed PCN with $\mathrm{CD} 3$ expression have been reported. ${ }^{5,6}$ However, few reports have compared the expression patterns of $\mathrm{CD} 3$ between initial and recurrent tumors of PCN. In the present case, the initial tumor of $\mathrm{CD} 3$-negative plasmacytoma was relapsed to $\mathrm{CD} 3$-positive $\mathrm{PM}$.

The reason for $\mathrm{T}$ antigen expression in $\mathrm{PCN}$ is not clearly understood. It might indicate that myeloma can arise from a normal minor subpopulation of B cells involved in immunoregulation. Aberrant T-cell antigen expression in B-cell lymphomas has been linked to host immunodeficiency. ${ }^{9}$ It has been suggested that EBV can promote T-cell antigen expression in B-cell tumors ${ }^{1}$ or could be a coincidental aberrancy associated with malignant change in plasma cells. ${ }^{2}$

Several factors have been associated with prognosis of PCN. Plasmablastic and anaplastic cytologic types are correlated with 

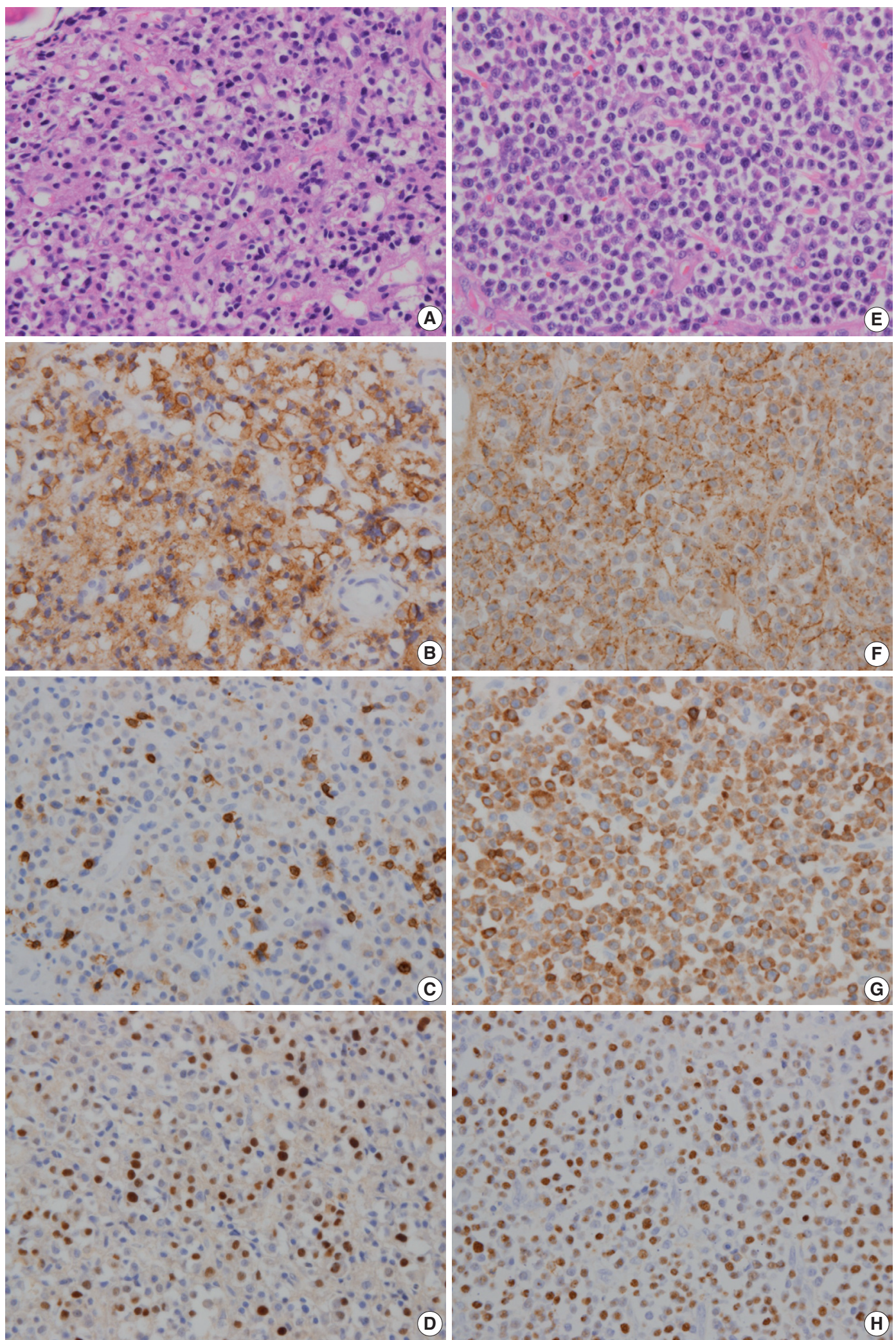

Fig. 2. In initial bone biopsy, the tumor was composed of differentiated plasma cells (A), which were positive for CD138 (B), but negative for CD3 (C). (D) The tumor cells were positive for Epstein-Barr virus-encoded RNA (EBER) in situ hybridization. (E) In relapsed soft tissue biopsy, the tumor was composed of medium-sized blastic cells admixed with smaller plasmacytic cells. Most of the tumor cells were strongly positive for CD138 (F) and CD3 (G). (H) The tumor cells were also positive for EBER ISH. 
Table 1. Summary of previously published PCN cases with CD3 expression

\begin{tabular}{|c|c|c|c|c|c|c|c|c|}
\hline Case No. & Diagnosis & Sex & Age (yr) & Location & CD20 & CD10 & EBV & Reference \\
\hline 1 & Myeloma & $\mathrm{M}$ & 62 & $\mathrm{BM}$ & $+/-$ & + & ND & Spier et al. ${ }^{2}$ \\
\hline 2 & Myeloma & $M$ & 69 & $\mathrm{BM}$ & ND & ND & ND & Yagci et al. ${ }^{5}$ \\
\hline 4 & Plasmablastic myeloma & $\mathrm{M}$ & 60 & Neck, thorax & - & ND & - & Oliveira et al. ${ }^{1}$ \\
\hline 5 & Plasmacytoma & $\mathrm{M}$ & 48 & Sacrum & - & - & ND & Oliveira et al. ${ }^{1}$ \\
\hline 6 & Anaplastic myeloma & M & 59 & $\mathrm{BM}$ & - & ND & - & Oliveira et al. ${ }^{1}$ \\
\hline 7 & Myeloma & $\mathrm{M}$ & 67 & Radius, LN & - & - & - & Tang et al. ${ }^{3}$ \\
\hline 8 & Myeloma & M & 62 & Mandible, BM & - & - & - & Luo et al. ${ }^{4}$ \\
\hline 9 & Myeloma & $\mathrm{F}$ & 60 & Skin & - & ND & - & Mishra et al. ${ }^{6}$ \\
\hline
\end{tabular}

PCN, plasma cell neoplasm; EBV, Epstein-Barr virus; M, male; BM, bone marrow; ND, not done; LN, lymph node; F, female.

more aggressive disease. ${ }^{10}$ Change to more aggressive phenotype is seen in relapsed cases of $\mathrm{PCN} .{ }^{10}$ However, an association with EBV has not been fully elucidated in previous cases of $\mathrm{CD} 3-$ expressing relapsed PCNs. In the present case, both initial differentiated PCN and relapsed plasmablastic tumor were positive for EBER ISH. This suggested that a gain of $\mathrm{CD} 3$ in PCN is associated with tumor progression to high-grade morphology and aggressive clinical course, which might be attributable to EBV infection. In this context, aberrant expression of $\mathrm{CD} 3$ might be useful as a phenotypic marker for disease progression of PCN and could be a candidate to direct further treatment in relapsed PCN.

\section{Conflicts of Interest}

No potential conflict of interest relevant to this article was reported.

\section{REFERENCES}

1. Oliveira JL, Grogg KL, Macon WR, Dogan A, Feldman AL. Clinicopathologic features of B-cell lineage neoplasms with aberrant expression of CD3: a study of 21 cases. Am J Surg Pathol 2012; 36: 1364-70.

2. Spier CM, Grogan TM, Durie BG, et al. T-cell antigen-positive mul- tiple myeloma. Mod Pathol 1990; 3: 302-7.

3. Tang YL, Chau CY, Yap WM, Chuah KL. CD3 expression in plasma cell neoplasm (multiple myeloma): a diagnostic pitfall. Pathology 2012; 44: 668-70.

4. Luo X, Kuklani R, Bains A. Dual CD3 and CD4 positive plasma cell neoplasm with indistinct morphology: a diagnostic pitfall. Pathology 2016; 48: 378-80.

5. Yagci M, Sucak GT, Akyol G, Haznedar R. Hepatic failure due to CD3+ plasma cell infiltration of the liver in multiple myeloma. Acta Haematol 2002; 107: 38-42.

6. Mishra P, Kakri S, Gujral S. Plasmablastic transformation of plasma cell myeloma with heterotropic expression of CD3 and CD4: a case report. Acta Clin Belg 2017; 72: 250-3.

7. Taddesse-Heath L, Meloni-Ehrig A, Scheerle J, Kelly JC, Jaffe ES. Plasmablastic lymphoma with MYC translocation: evidence for a common pathway in the generation of plasmablastic features. Mod Pathol 2010; 23: 991-9.

8. Vega F, Chang CC, Medeiros LJ, et al. Plasmablastic lymphomas and plasmablastic plasma cell myelomas have nearly identical immunophenotypic profiles. Mod Pathol 2005; 18: 806-15.

9. Sun J, Medeiros LJ, Lin P, Lu G, Bueso-Ramos CE, You MJ. Plasmablastic lymphoma involving the penis: a previously unreported location of a case with aberrant CD3 expression. Pathology 2011; 43: 54-7.

10. Gorczyca W. Atlas of differential diagnosis in neoplastic hematopathology. 3rd ed. Boca Raton: CRC Press, 2014; 359-81. 